\title{
Cuidador familiar do idoso em cuidados paliativos: o processo de morrer no domicílio
}

\author{
Family caregiver of elderly patients in palliative care: \\ the process of dying at home
}

Flavia Renata Fratezi ${ }^{1}$

Beatriz Aparecida Ozello Gutierrez ${ }^{1}$

${ }^{1}$ Universidade de São Paulo. Avenida Arlindo Bétio 1000, Ermelino Matarazzo. 03828-000 São Paulo SP. flaviafratezi@gmail.com

\begin{abstract}
This study sought to identify and analyze the significance of the process of dying for family caregivers of elderly patients in palliative care. It involved qualitative research with the use of interviews. The data were scrutinized by content analysis. The presence of chronic diseases that lead the elderly patient to require palliative care imposes a series of complex and ambivalent feelings on the family caregiver. The proximity and inevitability of death of the elderly patient exacerbate these feelings, but also lead the caregiver to reconsider how to handle this experience. Given this complexity, it becomes clear that the palliative tem need to work with family caregivers, to try to alleviate this situation.
\end{abstract}

Key words Death, Family, Elderly, Palliative care
Resumo Este estudo teve como objetivos: identificar e analisar o significado do processo de morrer para cuidadores familiares de pacientes idosos em cuidados paliativos. Tratou-se de pesquisa qualitativa com utilização de entrevista. Os dados foram analisados por conteúdo. A presença de doenças crônicas que levam o idoso a necessitar de cuidados paliativos impõe sobre o cuidador familiar sentimentos complexos e ambivalentes. A proximidade e inevitabilidade da morte do idoso colaboram para intensificar esses sentimentos, mas possibilitam ao cuidador resignificar como vivencia essa experiência. Diante desta complexidade, torna-se evidente que a equipe paliativista precisa colaborar junto ao cuidador familiar, no sentido de tentar amenizar essa situação.

Palavras-chave Morte, Família, Idoso, Cuidados paliativos 


\section{Introdução}

Em um idoso com doença crônica, a evolução para a morte ocorre quando o paciente encontra-se em um estado de fragilidade, com declínio das funções orgânicas e da qualidade de vida. Assim, é importante promover uma atenção integral ao paciente, envolvendo, também, seus familiares, pois a aproximação da morte do ente querido desperta na família e, em especial, no cuidador, desgaste físico, financeiro e emocional.

O processo de morte por doença crônica propicia a resolução das frustrações e pendências emocionais, legais, financeiras e sociais, além de favorecer uma mudança de atitude entre as pessoas ${ }^{1}$. Pensando assim, espera-se que a abordagem adequada dos sintomas físicos e psicológicos proporcione conforto ao paciente e possibilite a aproximação com a família e os amigos. Desta maneira, é de fundamental importância, tanto para o doente como para sua família, uma atenção relacionada ao suporte emocional e social de modo que tais pessoas enfrentem esse momento com mais tranquilidade e dignidade.

O morrer, além de ser um processo biológico, apresenta-se como uma construção social. Dessa forma, o processo do morrer pode ser vivido de distintas maneiras, de acordo com os significados compartilhados por esta experiência, porque esses significados são influenciados pelo momento histórico e pelos contextos sócio-culturais. Por isso, é importante conceber a morte como um processo e não como um fim, pois considerando que o paciente é um ser social e histórico, cuidá-lo em seu momento final significa entendê-lo, ouvilo e respeitá-lo. Dentro deste contexto, inseremse os cuidados paliativos, que, segundo a Organização Mundial da Saúde² (OMS), são os cuidados totais ativos aos pacientes cuja doença não responde mais ao tratamento curativo.

Nesta mudança de paradigma, entende-se que o objeto de cuidado dos profissionais da saúde considerados paliativistas não é apenas o doente fora de possibilidades terapêuticas e sua doença; amplia-se para a rede de relações familiares, existindo ainda, preocupação com o processo de luto antes e após o óbito do doente. As vantagens dos cuidados paliativos pautam-se na possibilidade de melhor enfrentamento da morte, promovendo sua aceitação e minimizando o sofrimento físico e psicológico, tanto do paciente como de sua família ${ }^{1}$. Portanto, diante de um paciente que recebe assistência paliativa, tornase fundamental a participação ativa da família no processo.
Assim, o ambiente familiar é um facilitador do tratamento diferenciado ao paciente, pois possibilita o surgimento de relações solidárias e responsáveis ${ }^{3}$. Além disso, promove a continuidade do suporte técnico, adicionados à segurança, à companhia, aos cuidados, ao carinho e ao afeto oferecidos pela família.

Nesse sentido, baseando-se na definição de cuidados paliativos da $\mathrm{OMS}^{2}$, que preconiza a busca da qualidade de vida dos familiares do paciente em processo de morrer, e o suporte para o enfrentamento deste processo, salienta-se que é fundamental conhecer o perfil do cuidador familiar, atentando-se para a subjetividade da tarefa de cuidar, pois esse conhecimento possibilitará a eficácia do planejamento e da implementação do cuidado e, consequentemente, sucesso na qualidade da assistência prestada ${ }^{4}$.

No contexto da família, cuidar de um doente requer um processo de adaptação de todos os membros ${ }^{5}$. Sabe-se que os membros da família são interconectados e dependentes uns dos outros, portanto, os comportamentos e as ações manifestados por um dos membros influenciam e são influenciados pelos demais, afetando todo o sistema familiar ${ }^{6}$.

Percebe-se que o sistema familiar pode modificar-se conforme a pessoa vai desenvolvendo a doença, pois ocorre uma mudança de papéis entre os familiares, alterando a estrutura e a dinâmica do grupo. Nas famílias que já não funcionavam bem, problemas de relacionamento podem persistir ou serem exacerbados, embora haja casos de familiares que reatam relações depois de um período de conflitos, tendo a doença, nesse caso, a função de unir ${ }^{7}$.

Desta forma, a maneira pela qual o sistema familiar e seus membros lidam com a situação entrelaça-se às relações interpessoais, transgeracionais e de parentesco desenvolvidas ao longo dos anos ${ }^{6}$.

Dentro da família, geralmente, existem pessoas que são delegadas a exercerem determinados papéis, tais como o de cuidador. Há, contudo, uma hierarquia para a escolha deste cuidador, que depende de fatores como: gênero, idade, fatores geracionais, grau de parentesco com o paciente, local de residência do cuidador, situação financeira daquele que presta o cuidado, tempo de que o cuidador dispõe, afetividade entre paciente e cuidador e personalidade daquele que cuida.

Considera-se que cuidar de idosos dependentes é um evento de vida normativo do curso de vida familiar, o que tem relação direta com a existência de uma norma sociocultural, segundo a 
qual cabe aos filhos o papel de cuidar dos pais idosos e aos cônjuges zelarem pelo cuidado de seus parceiros como uma questão de solidariedade, respeito e responsabilidade ${ }^{8}$.

Geralmente, a responsabilidade pelo cuidado fica a cargo de apenas um membro da família. Assim, os cuidadores de idosos estão expostos a um maior risco relacionado à morbidade física e psiquiátrica quando comparados à população em geral ${ }^{9}$. Portanto, os recursos sociais e pessoais de enfrentamento são importantes na avaliação subjetiva da tarefa de cuidar, pois predizem se a experiência será vivida de forma positiva ou negativa, o que terá influência direta sobre a qualidade do cuidado prestado ao idoso.

Cuidadores que vivenciam o cuidado como um evento negativo ligado a dano, ameaça, aborrecimento e tensão tendem a desempenhar suas funções abaixo de suas capacidades. O contrário ocorre quando as atitudes de enfrentamento são positivas, relacionadas, por exemplo, à aceitação da tarefa, a cuidar com resignação e amor, a sentir satisfação e prazer com o cuidado, à atribuição de significado à tarefa e ao aumento do senso de controle ${ }^{10,11}$.

Quando se trata de idosos fora de possibilidades terapêuticas, inclui-se às demandas de cuidado questões relativas à morte e à finitude, surgindo sentimentos como tristeza e desespero ${ }^{12}$. Nestes casos, a avaliação subjetiva e as estratégias de enfrentamento utilizadas devem ser investigadas, visando uma assistência adequada às pessoas envolvidas.

Diante desses aspectos, a pesquisa buscou identificar, na perspectiva de cuidadores familiares de idosos em cuidados paliativos, os sentimentos vivenciados em relação ao cuidado prestado; os sentimentos e significados atribuídos ao processo de morrer e à morte; as possíveis alterações na vida pessoal dos cuidadores; as expectativas em relação ao futuro dos pacientes; e as fontes de apoio.

\section{Métodos}

Para a realização da pesquisa, optou-se por um estudo qualitativo, com utilização de um roteiro de entrevista aberto e semi-estruturado. O roteiro foi desenvolvido a partir de revisão bibliográfica sobre o tema, sendo dividido em duas partes: 1) caracterização dos sujeitos da pesquisa e 2) questões relacionadas ao processo de morrer e à morte.

Os participantes foram nove cuidadores familiares principais de pacientes idosos em cuidados paliativos, assistidos pelo Programa de As- sistência Domiciliária do Hospital Universitário da Universidade de São Paulo (PAD-HU/USP). O PAD é um serviço que dispõe de equipe interprofissional para realizar atendimento tipo ambulatorial em domicílio. O programa tem como finalidade melhorar a qualidade de vida dos pacientes e de seus familiares; reintegrar o paciente ao ambiente sociofamiliar; orientar os cuidadores e os familiares quanto ao cuidado; prevenir reinternações; diminuir o tempo de internação, otimizando, assim, o uso de leitos hospitalares; e formar profissionais de saúde. Quando a pesquisa foi realizada, o programa atendia 103 pacientes, dos quais, 80 possuíam mais de 65 anos. Destes, 18 se encontravam em cuidados paliativos.

O número de sujeitos foi determinado pela saturação dos dados. Os critérios de inclusão na amostra foram: 1) Ser cuidador familiar principal de pacientes idosos em cuidados paliativos usuários do PAD/HU-USP; 2) Aceitar participar da pesquisa e estar de acordo com as condições descritas no Termo de Consentimento Livre e Esclarecido.

As entrevistas ocorreram no domicílio do paciente, logo após a visita da equipe do PAD/HUUSP. No momento da visita, a pesquisadora solicitava ao cuidador familiar a participação na pesquisa, seguindo com a explicação da mesma. Nos casos em que o familiar se dispunha a participar, eram agendados data e horário da entrevista, segundo a disponibilidade do participante.

As entrevistas foram transcritas na íntegra e analisadas de acordo com a análise de conteúdo proposta por Minayo ${ }^{13}$. As categorias de análise surgiram a partir de temas emergentes.

A pesquisa foi aprovada pela Comissão de Ensino e Pesquisa (COMEP) e pelo Comitê de Ética em Pesquisa, órgãos ligados ao Hospital Universitário da Universidade de São Paulo (CEP/ HU-USP). Contou-se, ainda, com a autorização da administração do PAD/HU-USP. Todos os participantes do estudo assinaram o Termo de Consentimento Livre e Esclarecido e foram respeitadas as normas da Resolução 196/ 96 do Conselho Nacional de Saúde do Ministério da Saúde. Visando garantir o anonimato dos participantes, seus nomes foram substituídos por pseudônimos baseados em nomes de pedras preciosas.

\section{Resultados e discussão}

Dentre os nove cuidadores familiares entrevistados, oito eram mulheres e um era homem, com idade média de 62,6 anos, variando de 49 a 75 anos. Constatou-se que quatro eram esposas, três 
eram filhas, um era filho e uma era nora do paciente. Uma cuidadora era divorciada e os demais eram casados. Sobre a ocupação, quatro eram do lar, três aposentados, um pensionista e um técnico em agrimensura. Quando questionados sobre a escolaridade, sete cuidadores disseram possuir primeiro grau incompleto e apenas dois tinham o segundo grau completo. Com relação à moradia, cinco cuidadores moravam com cônjuge e outros familiares, incluindo filhos, netos e sogra; três residiam com o cônjuge; e uma morava com os pais. Sobre a religião, uma cuidadora revelou estar afastada da atuação religiosa, uma disse ser católica e espírita e os demais relataram ser católicos. A média de tempo de cuidado foi de dois anos e seis meses, variando de dois meses a oito anos, considerados na data da entrevista.

Em todos os casos, verificou-se que um familiar foi escolhido, ou designado, para exercer o papel de cuidador. Por isso, nem sempre o cuidado a um paciente dependente está atrelado a sentimentos de amor e afeto. Acredita-se que, ao cuidar de um paciente fora de possibilidades terapêuticas, se a escolha do cuidador baseou-se em sentimentos de obrigação moral, será necessário um esforço maior do cuidador para resignificar sua relação com o paciente e desenvolver estratégias para lidar com a finitude.

As entrevistas realizadas originaram seis categorias de análise referentes aos cuidadores familiares de pacientes idosos em cuidados paliativos: sentimentos vivenciados perante o cuidado; sentimentos e significados atribuídos ao processo de morrer e à morte; processo de cuidar e as dificuldades enfrentadas; vida pessoal dos cuidadores; expectativas em relação ao futuro do paciente; e fontes de apoio, como descrito a seguir.

\section{Sentimentos vivenciados pelos cuidadores perante o cuidado prestado}

As respostas obtidas dos cuidadores incluíram tanto sentimentos positivos como negativos em relação ao cuidado prestado ao paciente. Dentre os sentimentos positivos, surgiram: zelo, carinho e gratificação, os quais revelaram a vontade do cuidador de estar ao lado do seu ente querido o máximo de tempo possível. Mesmo que a tarefa seja dispendiosa, a relação de afeto entre o cuidador e o doente torna-se um fator que ameniza as dificuldades que o cuidar impõe, conforme pode ser observado nas frases:

Trabalho, o doente sempre dá pra gente, mas eu tenho muito carinho por ele. Eu cuido dele! (Topázio)
Eu me sinto bem porque eu gosto de cuidar dela. [...] eu to tentando ser útil! (Safira)

Esses sentimentos também estiveram relacionados com encontrar um sentido para aquilo que se faz e atribuir um significado para o sofrimento, podendo-se inferir que, mesmo diante da consciência de que a morte é inevitável, para os cuidadores algo pode ser feito, como por exemplo, oferecer dignidade ao paciente durante seu processo de morrer.

Os sentimentos negativos relatados: tristeza, incômodo e preocupação/ inquietação, foram decorrentes da sensação de impotência, pois por mais que o cuidador se dedique, não observa melhora no quadro do paciente.

Eu não queria ver ele nessa situação de dependência total, entendeu? (Jade)

Você tem que ficar aqui igual um guarda. Você dorme mal, eu vou dormir duas horas da manhã, você dorme mal, toca o telefone de madrugada, você já: 'A mamãe!'. (Ametista)

A frase acima ilustra a situação de preocupação / inquietação, que pode dificultar o enfrentamento pessoal ${ }^{14}$, pois o cuidador não consegue se desligar, nem se dedicar a outras atividades. Além disso, saber que o seu familiar está próximo da morte intensifica esses sentimentos, primeiro porque o cuidador fica aguardando a chegada da notícia do falecimento; e também o coloca frente à sua própria finitude.

Ressalta-se que a tristeza pode ser entendida como parte da fase de depressão pela qual passam os pacientes e os familiares durante o processo de morrer ${ }^{15}$. Essa fase é importante para que o cuidador, após ter passado por um intenso período de tristeza e sofrimento, aceite a morte do paciente como algo inevitável, que trará alívio tanto para o familiar como para o idoso.

\section{Sentimentos e significados vivenciados pelos cuidadores em relação ao processo de morrer e à morte}

Os sentimentos e significados em relação ao processo de morrer e à morte estiveram interligados a aspectos como: relação prévia entre o paciente e o cuidador; tempo de cuidado; crenças religiosas e espiritualidade; avaliação subjetiva do cuidado; rede de suporte social de que o cuidador dispõe, dentre outros. Estudo com profissionais de enfermagem identificou que os significados atribuídos ao processo de morrer e à morte foram: coisa natural, fim de tudo, passagem, saudade, vida após a morte e perda ${ }^{16}$. Já, no presente estudo, surgiram respostas como: negação 
da morte e o processo de aceitação da morte, visualizando-a como um descanso; uma passagem e um processo natural da vida.

Acredita-se que encarar a morte como descanso, passagem e fato natural da vida é uma estratégia de enfrentamento que permite que a experiência de lidar com um paciente em cuidados paliativos seja menos sofrida e desgastante.

A negação da morte caracteriza-se como a primeira fase do processo de morrer pela qual passam os familiares e os pacientes ${ }^{15}$. Ainda, a negação é como um amortecedor e uma anestesia temporária, que possibilita aos cuidadores e pacientes ganharem forças e mobilizarem suas defesas para lidarem com a situação ${ }^{17}$.

Por outro lado, a aceitação da morte foi descrita como a última fase do processo de morrer vivenciada pelos familiares e pelo paciente ${ }^{15}$. Nesse momento, aceitam-se os seus próprios limites, a finitude do ser humano e a proximidade da morte. As frases a seguir ilustram os sentimentos de negação e aceitação da morte, respectivamente.

A morte prá mim é uma coisa, é tudo de ruim, é tudo de ruim. Eu não tô preparada pra ela não. Acho que não tem coisa pior do que a morte, eu acho, pelo menos no meu ver. (Safira)

Eu to aceitando aos pouquinhos, né. É como diz minha cunhada, outro dia ela veio aí, falou: é um preparo, ele tem que desapegar e a gente também, né. Ele tem que se desapegar da vida, das pessoas, e a gente também tem que ir se desapegando dele, né, porque ele tem pouco tempo, eu acredito. Às vezes eu procuro aceitar, às vezes eu fico...

Eu acho que é normal, né... revolta, raiva, aceitação! Essas três coisas que têm que se entrelaçar, pra aceitar mesmo, né! Não se pode remediar! Não pode mudar, não é verdade? (Jade)

No começo foi difícil de aceitar essas coisas assim, né. Mas agora eu to me conformando! (Esmeralda)

\section{O processo de cuidar e as dificuldades enfrentadas pelos cuidadores}

Os cuidadores familiares revelaram que as dificuldades existentes diante do processo de cuidar compreendem: ausência de conhecimento técnico, alterações emocionais, desgaste físico e dificuldades financeiras, por exemplo:

[...] Minha vida financeira virou uma droga, porque não entra dinheiro. (Ametista)

Eu fiquei assim meia perdida, sabe... quando ele veio do hospital eu não sabia o remédio, eu não sabia negócio de insulina. Ele nunca tomou insulina na vida dele. Então, prá mim foi meio complicado... Eu tinha pavor de insulina... Ele também tinha pavor de insulina. Dá trabalho! A gente tem um trabalhão! (Topázio)

Até depois de um ano mais ou menos, eu tive depressão, tive que tomar antidepressivo. Tive não, ainda to [...] to no tratamento, tudo, mas to levando. (Diamante)

Encontra-se que o ato de cuidar é um aprendizado constante, que se modifica com o avançar da doença e de acordo com as necessidades do doente $^{14}$. Essa atividade torna-se mais complexa com o passar do tempo, pois o paciente fica mais dependente. Desta forma, exige que o cuidador aprenda e desenvolva novas maneiras de cuidar no enfrentamento do cotidiano. Assim, o papel de cuidador é aprimorado ao longo do tempo, especialmente impulsionado pela demanda de cuidado que se modifica. Muitas vezes, os cuidadores não possuem um profissional que os oriente com relação à execução das tarefas, tendo que aprender a realizá-las sozinhos.

Quando os cuidadores não têm um suporte adequado e equilíbrio emocional, estas alterações podem causar problemas psicológicos, necessitando de cuidados especiais. As dificuldades emocionais narradas pelos familiares podem decorrer da dificuldade em lidar com o sofrimento do paciente e da tarefa de cuidar, bem como da proximidade da morte. Como dito anteriormente, a ameaça da morte leva o familiar a ter que aceitar a perda do outro, além de conviver com a realidade da sua própria finitude.

\section{A vida pessoal dos cuidadores}

Em se tratando de vida pessoal, a maioria dos participantes relatou alterações após terem assumido o papel de cuidador. A percepção do cuidador em relação à forma como as tarefas que desempenha afetam sua vida e sua rotina interfere diretamente na qualidade do cuidado dispensado ao paciente ${ }^{10}$.

Ao focalizar a vida pessoal dos cuidadores, detectaram-se discordâncias nos discursos, enquanto para alguns entrevistados a alteração na vida pessoal foi negativa, para outros foi positiva. A alteração negativa esteve associada à perda de emprego, mudança de domicílio e diminuição da vida social. Percebe-se que os entrevistados negligenciaram sua vida ou parte dela, o que pode gerar sensações de tristeza, isolamento, perda da liberdade e descuido, conforme demonstra a frase:

Há seis anos atrás, eu morava no interior, eu era artesã, fazia artesanato, montava barraca, colocava minhas coisas em exposição, e depois que ela ficou doente eu larguei tudo e vim pra cá. (Safira) 
Então eu me fechei igual um caramujo pra ficar com ela até o fim. Então eu só acho que eu vou voltar às minhas atividades quando a mamãe partir, todas nós! (Ametista)

Em contrapartida, destacaram-se mudanças positivas de vida:

Eu consegui até parar até de fumar por causa disso. Eu fumei mais de trinta anos, mais de um maço por dia. Prá cuidar dele eu falei, não. Eu falei: eu tenho que largar de fumar porque eu tenho uma pessoa prá mim cuidar. Mas foi uma beleza, nem depressão apareceu! (Rubi)

Nenhuma dificuldade, hoje em dia nenhuma. No começo era difícil, mas agora a gente tira de letra! (Safira)

Os fatos relatados mostraram que o cuidado e a proximidade da morte podem estimular a busca por novos significados e sentidos para a vida, levando a uma mudança de vida por parte do cuidador, que passa a desenvolver e expressar novas atitudes e novos hábitos, valorizando outras prioridades.

Diante dessas alterações relatadas pelos cuidadores em suas vidas, as entrevistas demonstraram que os cuidadores desenvolveram resiliência para lidar com a situação. Nesse sentido, concluise que o sofrimento e os desafios de cuidar de alguém fora de possibilidades terapêuticas possibilitaram aos cuidadores desenvolverem autoconhecimento e descobrirem potencialidades desconhecidas para enfrentarem a situação. Em alguns casos, ao deparar com as dificuldades, a única solução que o familiar encontra é a de enfrentar a adversidade, por isso cria alternativas que mudam a sua maneira de viver na tentativa de superar as dificuldades da melhor forma possível.

\section{Expectativas dos cuidadores em relação ao futuro do paciente}

Os significados atribuídos ao processo de morrer e à morte predizem as expectativas que os cuidadores têm em relação ao futuro do paciente. Percebe-se que os discursos advindos dos familiares que não aceitam a morte do paciente tendem, em maior escala, a manter esperança de cura, enquanto os familiares que apresentam uma tendência à aceitação da morte, em geral, conformam-se com a situação.

Eu espero que ela tenha uma melhora, tenho esperança. Eu acho que tudo é válido na vida, a gente luta pro melhor, né! (Citrino)

Infelizmente a gente não espera muita coisa, né. Não espera muita coisa. Olha ela, coitadinha, o que que a gente espera daquilo lá? (Safira)
A esperança de cura auxilia o familiar a lidar com o sofrimento e a prover suporte físico e emocional ao paciente ${ }^{18}$. Portanto, manter esperança auxilia os cuidadores familiares a reduzirem seus sentimentos de angústia, podendo auxiliá-los a aceitar a perda.

Em contrapartida, alguns autores apontaram que se conformar com a situação pode configurar-se como importante para a aceitação do processo de morrer, pois a probabilidade de ocorrer uma mudança é pequena ou inexistente ${ }^{14}$. Por mais que o cuidador se esforce, a morte do paciente é inevitável, portanto, conformar-se é uma estratégia para amenizar o sofrimento.

\section{As fontes de apoio encontradas pelos cuidadores}

As expectativas que os cuidadores têm quanto ao futuro do paciente e os sentimentos e significados atribuídos ao cuidado, ao processo de morrer e à morte sofrem forte influência das fontes que eles buscam para receberem apoio.

As redes de apoio são importantes para auxiliar o indivíduo a desenvolver estratégias e competências para enfrentar as adversidades, ajudando em seu manejo e fornecendo suporte emocional. Assim, as fontes de apoio que os cuidadores deste estudo buscaram para enfrentarem o processo de morrer e a morte foram: o apoio social informal, o apoio social formal e o apoio espiritual, conforme ilustrado a seguir.

$E$ E, a gente tem uns amigos... Esse aqui é como um irmão da gente. São uns vizinhos que não tem o que pague. Porque só um carinho, alguma coisa que a pessoa dá pra gente, a gente já agradece. Colaborou muito com meu marido... (Topázio)

[...] tem uma médica clínica que ela me acompanha direto. E ta me ajudando! (Rubi)

Tem uma energia muito forte, que move assim, que por mais errado que eu acho que vai dar [...] então, eu não posso te falar, é uma energia maior que acontece! (Ágata)

As fontes de apoios informais foram provenientes, principalmente, da família e de amigos, e o apoio social formal adveio dos serviços de saúde. Já o apego à espiritualidade apareceu de forma unânime nas entrevistas, podendo ser considerado uma tentativa de alívio e consolo para o sofrimento que proporciona certa conformidade com a situação.

Tem-se que a relação de ajuda pode ser considerada como essencial para auxiliar os cuidadores a lidarem com o processo de morrer dos pacientes fora de possibilidades terapêuticas, bem 
como com os encargos advindos da tarefa de cuidar.

\section{Considerações finais}

O processo de morrer pode ser vivido de maneiras diferentes por cada indivíduo, dependendo do contexto social, histórico e cultural em que ele está inserido. O processo de morrer e a morte do outro despertam sentimentos de medo, raiva, impotência, insegurança, estando mais relacionado à perda e à separação do que a um processo natural da vida. Entretanto, a não aceitação desse processo como parte do ciclo de vida tem relação com o medo do desconhecido, uma vez que ninguém sabe o que acontece após a morte.

Apesar da presença da dor e do sofrimento no final da vida, o processo de morrer e a morte devem ser encarados como sendo momentos sublimes, dotados de elevação espiritual, de expressão de sentimentos, de atos solidários para com o outro e de coragem. Por isso, nesse estudo buscou-se identificar como os cuidadores familiares significam a morte e o processo de morrer de seus parentes idosos em cuidados paliativos.

Acredita-se que os dados encontrados nesta pesquisa podem contribuir para a valorização do cuidador e do sistema familiar como um todo dentro do processo de morrer, pois este impõe um desafio para as famílias, afetando sua estrutura e sua dinâmica e infligindo a necessidade de readaptação à nova situação. Nesse sentido, é importante o planejamento de intervenções de orientação, suporte e apoio para toda a família, especialmente para o cuidador familiar.

\section{Colaboradores}

FR Fratezi e BAO Gutierrez participaram igualmente de todas as etapas da elaboração do artigo. 


\section{Referências}

1. Burlá C. Paliação: Cuidados ao fim da vida. In: Freitas EV, Py L, Cançado FAX, Gorzoni ML, organizadores. Tratado de Geriatria e Gerontologia. 2a ed. Rio de Janeiro: Guanabara Koogan; 2006. p. 732-739.

2. National cancer control programmes: policies and managerial guidelines. $2^{\text {a }}$ ed. Geneve: World Health Organization; 2002.

3. Soares MVB. Pacientes X cuidadores: os dois pólos da relação no cuidado domiciliar da AIDS [monografia]. Ribeirão Preto (SP): Faculdade de Filosofia, Ciências e Letras de Ribeirão Preto, Universidade de São Paulo; 2000.

4. Floriani CA. Cuidador familiar: sobrecarga e proteção. Rev Bras Cancerologia 2004; 50(4):341-345.

5. Angelo M, Bousso RS. Fundamentos da assistência à família em saúde. [periódico na Internet]. [acessado 2008 jun 26]. Disponível em: http://www.idssaude.org. br/enfermagem

6. Falcão DVS. Doença de Alzheimer: um estudo sobre o papel das filhas cuidadoras e suas relações familiares [tese]. Brasília (DF): Universidade de Brasília; 2006.

7. Silveira TM. O sistema familiar e os cuidados com pacientes idosos portadores de distúrbios cognitivos. Textos Envelhecimento 2000; 3(4):23-31.

8. Neri AL, Fortes ACG. A dinâmica estresse e enfrentamento na velhice e sua expressão no prestar cuidados a idosos no contexto da família. In: Freitas EV, Py L, Cançado FAX, Gorzoni ML, organizadores. Tratado de Geriatria e Gerontologia. 2a ed. Rio de Janeiro: Guanabara Koogan; 2006. p. 1277-1288.

9. Giacomin KC, Uchoa E, Lima-Costa MFF. Bambuí: a experiência do cuidado domiciliário por esposas de idosos dependentes. Cad Saude Publica 2005; 21(5):1509-1518.

10. Sommerhalder C. Significados associados à tarefa de cuidar de idosos de alta dependência no contexto familiar [dissertação]. Campinas (SP): Universidade Estadual de Campinas; 2001.
11. Sommerhalder C, Neri AL. As várias faces do cuidado e do bem-estar do cuidador. In: Neri AL, organizadora. Cuidar de idosos no contexto da família - questões psicológicas e sociais. Campinas (SP): Alínea; 2002. p. 9-63.

12. Doll J, Py L. O idoso na relação com a morte. In: Neri AL organizadora. Qualidade de vida na velhice: um enfoque multidisciplinar. Campinas (SP): Alínea; 2007. p. 279-300.

13. Minayo MCS. O desafio do conhecimento: pesquisa qualitativa em saúde. $6^{a}$ ed. São Paulo: HucitecAbrasco; 2004.

14. Cattani RB, Girardon-Perlini NMO. Cuidar do idoso doente no domicílio na voz de cuidadores familiares. Revista Eletrônica de Enfermagem 2004; 6(2): 254-271.

15. Kubler-Ross E. Morte: estágio final da evolução. Rio de Janeiro: Nova Era; 1996.

16. Gutierrez BAO. O processo de morrer no cotidiano do trabalho dos profissionais de enfermagem de Unidades de Terapia Intensiva [tese]. São Paulo: Universidade de São Paulo; 2003.

17. Kovács MJ. Educação para a morte: temas e reflexões. São Paulo: Casa do Psicólogo: Fapesp; 2003.

18. Pereira LL, Dias ACG. O familiar cuidador do paciente terminal: o processo de despedida no contexto hospitalar. Psico 2007; 38(1):55-65.

Artigo apresentado em 05/05/2009

Aprovado em 04/11/2009

Versão final apresentada em 22/11/2009 